\title{
BMJ Open Reasonable adjustments for people with intellectual disability in acute care: a scoping review of the evidence
}

\author{
Mairead Moloney, ${ }^{1}$ Therese Hennessy, ${ }^{1}$ Owen Doody (i) ${ }^{2}$
}

To cite: Moloney M, Hennessy T, Doody 0. Reasonable adjustments for people with intellectual disability in acute care: a scoping review of the evidence. BMJ Open 2021;11:e039647. doi:10.1136/ bmjopen-2020-039647

- Prepublication history for this paper is available online. To view these files, please visit the journal online (http://dx.doi org/10.1136/bmjopen-2020039647).

Received 23 April 2020 Revised 14 January 2021 Accepted 23 January 2021
D) Check for updates

(c) Author(s) (or their employer(s)) 2021. Re-use permitted under CC BY-NC. No commercial re-use. See rights and permissions. Published by BMJ.

${ }^{1}$ Department of Nursing and Midwifery, Faculty of Education and Health Sciences, University of Limerick, Limerick, Ireland ${ }^{2}$ Department of Nursing and Midwifery, Faculty of Education and Health Sciences, Health Research Institute, Health Implementation Science and Technology, University of Limerick, Limerick, Ireland

Correspondence to Dr Owen Doody; owen.doody@ul.ie

\section{ABSTRACT}

Objectives People with intellectual disability are vulnerable in terms of health service provision due to increased comorbidity, higher dependency and cognitive impairment. This review explored the literature to ascertain what reasonable adjustments are evident in acute care to support people with intellectual disability, ensuring they have fair access and utilisation of health services.

Design Scoping review.

Setting Acute care settings.

Methods Five databases were systematically searched to identify studies that reported on the implementation of reasonable adjustments. Authors worked in pairs to screen studies for inclusion, data were extracted and charted and findings were synthesised according to content and themes.

Results of the 7770 records identified, six studies were included in the review. The volume of evidence was influenced by specific inclusion criteria, and only papers that reported on the actual implementation of a reasonable adjustment within an acute care setting were included. Many papers reported on the concept of reasonable adjustment; however, few identified its applications in practice.

Conclusions The scoping review highlights a lack of research on the practice and implementation of reasonable adjustments within acute care settings. There is a need for increased support, education and the provision of intellectual disability specialists across acute care settings.

\section{BACKGROUND}

The WHO identifies intellectual disability as a significantly reduced ability to understand new or complex information and to learn and apply new skills (impaired intelligence), resulting in a reduced ability to cope independently (impaired social functioning), and which occurs before adulthood with a lasting effect on development. ${ }^{1}$ Disability is not conceptualised based on a person's level of ability but rather the extent to which environmental factors support the person's participation and inclusion in society ${ }^{1}$ or the socially constructed barriers that limit a person's everyday activities. ${ }^{2}$ Such barriers are clearly evident within healthcare structures, and some healthcare professionals lack

\section{Strengths and limitations of this study}

The review design allowed for a broad review of published literature.

- The review focus was solely on reasonable adjustments in acute healthcare settings.

- Only English language research were included in the review.

- A formal quality appraisal process was not included in the study.

- The review highlights evidence of reasonable adjustments made in acute care settings.

the specific knowledge, skill and education to provide a person centred service to people with intellectual disability. ${ }^{3}$ Such a deficit creates a gap between the health needs of people with intellectual disability and service provision. ${ }^{4}$ To address such deficits, it is advocated that reasonable adjustments are made to clinical policies and practices to ensure that people with intellectual disabilities and other disadvantaged groups are treated equitably with regard to healthcare access and provision. ${ }^{5-8}$ Reasonable adjustments are positive measures that can be implemented at an organisational, system or individual level to address the healthcare inequalities experienced by people. ${ }^{6}$

At an individual level, people with intellectual disability experience poorer health, ${ }^{9} 10$ have complex needs, ${ }^{11} 12$ greater comorbidities, ${ }^{1314}$ present more often for treatment, ${ }^{1516}$ experience increased polypharmacy ${ }^{17} 18$ and die younger ${ }^{19}{ }^{20}$ compared with the general population. At an organisational and system level, people with intellectual disability experience greater health disparities ${ }^{21}{ }^{22}$ which results in unmet health needs, ${ }^{23}{ }^{24}$ as health service providers are often ill-prepared and ill-equipped to support people with intellectual disability. In addition, healthcare professionals' inadequate knowledge and stereotypical-based attitudes contribute to the experience of health discrimination. ${ }^{25} 26$ 
Despite international recommendations, ${ }^{27-29}$ people with intellectual disability remain largely invisible to routine data collection and analysis in research studies. ${ }^{30}$ Seeking to address such inequalities is essential of any modern healthcare system, and the United Nation's (UN) Convention on the Rights of Persons with Disabilities $^{31}$ requires countries and parties of the state to recognise that people with intellectual disability have the same rights to enjoy to the highest attainable standard of health without discrimination. The UN convention along with National Equality or Disability Acts places a responsibility on all public services, including acute hospitals, to make reasonable adjustments to ensure that people with intellectual disability are not disadvantaged. ${ }^{32}$

Despite legislation, policy and practice guidelines, people with intellectual disability continue to experience many barriers to accessing services, ${ }^{33}$ including required healthcare ${ }^{534}$ Such barriers include: structural barriers (eg, physical access to buildings and transport issues), financial barriers (eg, affordable medicines), and attitudinal barriers (eg, failure to understand and listen to the person with intellectual disability). ${ }^{5}$ In addition, despite many initiatives undertaken to address Mencap's groundbreaking report in the $\mathrm{UK},{ }^{25}$ people with intellectual disability continue to have poor experiences during admissions to acute hospitals. ${ }^{35}$ Insufficient evidence is available regarding initiatives that have been implemented and their effectiveness. ${ }^{36}$ One such initiative is the use of 'passports', Atkinson ${ }^{37}$ and Northway et $a l^{8}$ have identified that passports can improve quality of care within intellectual disability services. However, similar research regarding the use of passports is lacking within acute care.

Within acute care settings, healthcare professionals acknowledge that they experience difficulties in truly hearing and listening to people with intellectual disability resulting in an inability to adequately meet their healthcare needs. ${ }^{39}$ It is essential that all healthcare professionals, including nurses, are able to anticipate and support the holistic needs of people with intellectual disability in the acute care setting. ${ }^{40}$ Holistic healthcare is central to the practice of caring where the person should be the focus, giving attention to the context in which the person lives, including their family, community and culture. ${ }^{41}$ The humanistic approach to nursing care is evidenced in person-centred practice, where each person should be assessed and treated on an individual basis and their care centred on their needs rather than the needs of the service. ${ }^{42}$ Person-centred care and the rights of people with intellectual disability can be supported within acute care settings through the adoption of reasonable adjustments, as far as possible, ensuring people with intellectual disability receive equitable and appropriate healthcare provision.

As reasonable adjustments are intended to overcome the disadvantage experienced in accessing and receiving services/care, adjustments must be made to ensure a person with intellectual disability receives the same level of care provided to others. Reasonable adjustments can occur at system and individual levels. System-level reasonable adjustments include strategic approaches for addressing barriers that could potentially impede people with intellectual disability from accessing a service, ${ }^{43}$ such as wheelchair accessibility, accessible information, colour-coded signage, access to interpreters or use of health passports. There are many factors that can influence the adoption of reasonable adjustments in practice such as: the ability of the organisation to align the intervention with the person's needs; the practicability of making the change; the size of the organisation; the cost and resources needed; and whether any changes have already been implemented. ${ }^{6}$ Individual-level reasonable adjustments are specifically tailored to a person with intellectual disability, which can be identified through assessment and/or discussion with the person, their family or General Practitioner (GP). ${ }^{6}$ Acknowledging the importance of supporting the holistic needs of people with intellectual disability using a person-centred approach to care and the fact that no review of reasonable adjustments for people with intellectual disability were found by the authors, the focus of this scoping review of the literature is to identify evidence of individual level reasonable adjustments in acute care settings.

\section{METHOD}

A scoping review methodology was chosen due to the broad, multifaceted nature of intellectual disability. Scoping reviews provide an overview of the topic and describe the efforts of available research and thus identify gaps in the literature. ${ }^{44}$ The review was defined by the following question 'what reasonable adjustments are evident in acute care for people with intellectual disability?'. The authors were guided by the Joanna Briggs Institute Methodology ${ }^{45}$ process for scoping reviews. Inclusion criteria were set (table 1), and a search strategy was developed (table 2). Searches were conducted across five databases; MEDLINE, CINAHL, Academic Search Complete, PsycArticles and PsycINFO (OD) to identify papers on the topic. Search strings were developed (table 2), and search words were used in title and abstract screening for S1 and S2 using the Boolean operator OR (OD). Search 3 combined S1 and S2 using the Boolean operator AND (OD). Papers included for full-text review were checked for citations using the forward and backward chaining process to identify any additional papers for inclusion. Within the search process all records were exported to Endnote X9 (Clarivate Analytics, Pennsylvania, USA) and duplicates removed (OD). Titles and abstracts were then screened by two reviewers independently (OD and TH) against the inclusion criteria. The remaining papers were then retrieved for full-text review by paired reviewers working independently (OD, TH and $\mathrm{MM}$ ) and reasons for exclusion were recorded and reported (figure 1).

Any differences between reviewers at each stage of the process were resolved through discussion or with the third 


\begin{tabular}{|c|c|c|}
\hline & Include & Exclude \\
\hline Participants & $\begin{array}{l}\text { Persons with } \\
\text { intellectual disability. }\end{array}$ & $\begin{array}{l}\text { Non-intellectual } \\
\text { disability population. }\end{array}$ \\
\hline Timeline & $\begin{array}{l}\text { January } 2006 \text { to } 30 \\
\text { March } 2020 .\end{array}$ & $\begin{array}{l}\text { Prior to } 1 \text { January } 2006 \\
\text { (UN Convention). }\end{array}$ \\
\hline Concept & $\begin{array}{l}\text { Papers that identify } \\
\text { a reasonable } \\
\text { adjustment made } \\
\text { for a person/s with } \\
\text { intellectual disability. }\end{array}$ & $\begin{array}{l}\text { Papers that fail to } \\
\text { identify a reasonable } \\
\text { adjustment made } \\
\text { for a person/s with } \\
\text { intellectual disability. }\end{array}$ \\
\hline Context & $\begin{array}{l}\text { Acute inpatient care } \\
\text { setting. }\end{array}$ & $\begin{array}{l}\text { Outpatient clinics or } \\
\text { screening procedures. }\end{array}$ \\
\hline Language & $\begin{array}{l}\text { Papers publishes in } \\
\text { English. }\end{array}$ & Non-English papers. \\
\hline $\begin{array}{l}\text { Types of } \\
\text { studies }\end{array}$ & $\begin{array}{l}\text { Quantitative, } \\
\text { qualitative, mixed } \\
\text { methods study and } \\
\text { papers that present a } \\
\text { case study. }\end{array}$ & $\begin{array}{l}\text { Literature reviews, } \\
\text { discussion and } \\
\text { opinion papers with no } \\
\text { evidence of reasonable } \\
\text { adjustment made. }\end{array}$ \\
\hline
\end{tabular}

reviewer. Data were extracted from papers included in the scoping review using a data extraction tool developed by the reviewers (table 3) and used to present data in tabular form. Finally, a narrative synthesis is presented in the findings in order to present/chart the results as related to the review question to portray the current evidence of reasonable adjustments for people with intellectual disability in acute care settings. This review is reported in line with the Preferred Reporting Items for Systematic reviews and Meta-Analyses extension for Scoping Reviews (PRISMA-ScR) Checklist. ${ }^{46}$

\section{Patient and public involvement statement}

Patients or the public were not involved in the design, conduct, reporting or dissemination of this review.

\section{RESULTS}

\section{Included studies}

Figure 1 contains a PRISMA flow chart of the screening process, database searches identified 7767 records across five databases, with a further three identified from other sources totalling 7770. After duplicates were removed 3803 records remained for title and abstract review. Following title and abstract screening, 19 records were

\begin{tabular}{lll}
\hline Table 2 & Search process & \\
\hline Search & Terms & Field \\
\hline S1 & $\begin{array}{l}\text { intellectual disabilit }{ }^{*} \text { OR mental } \\
\text { retardation OR learning disabilit } \\
\text { developmental disabilit* }\end{array}$ & $\begin{array}{l}\text { Title OR } \\
\text { Abstract }\end{array}$ \\
S2 & $\begin{array}{l}\text { reasonable adjustment } \\
\text { accommodation }{ }^{*} \text { OR reasonable } \text { access }^{*}\end{array}$ & $\begin{array}{l}\text { Title OR } \\
\text { Abstract }\end{array}$ \\
S3 & S1+S2 & \\
\hline
\end{tabular}
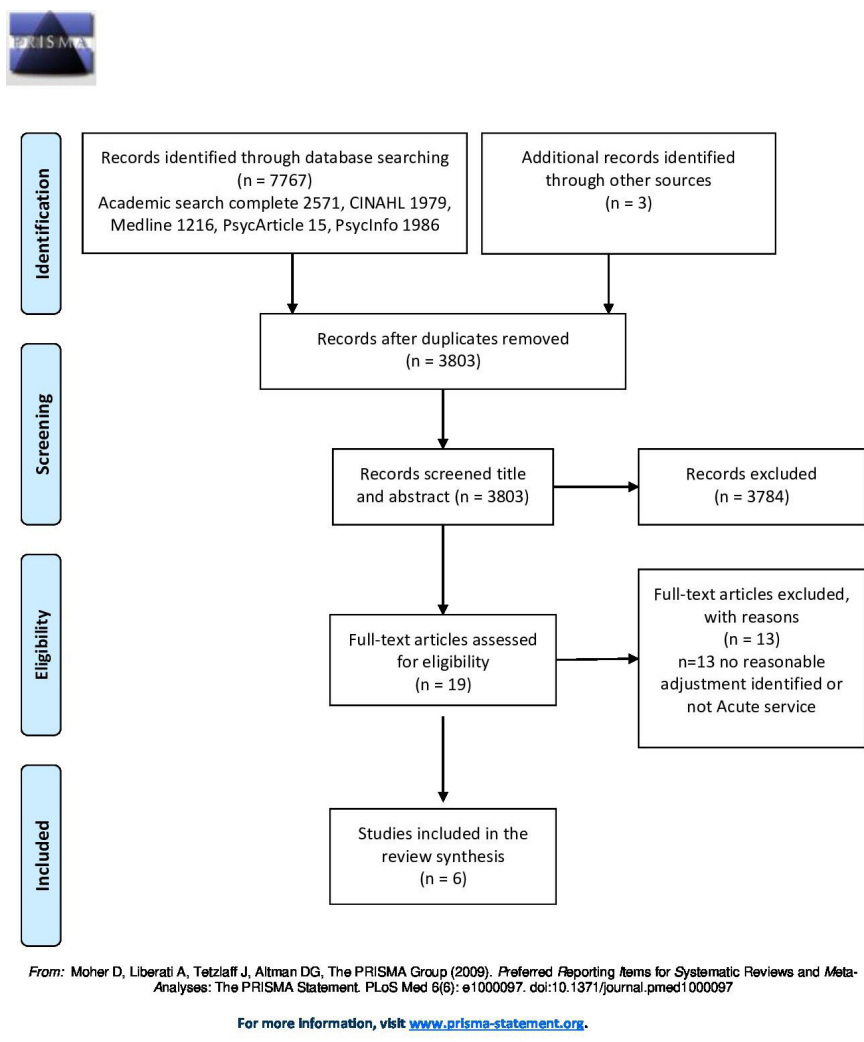

Figure 1 PRISMA 2009 flow diagram. ${ }^{91}$ PRISMA, Preferred Reporting Items for Systematic Reviews and Meta-Analyses.

retained for full-text screening of which six studies met the inclusion criteria for this scoping review.

\section{Study characteristics}

Table 3 provides a summary of the included studies. Of the six included papers one was from Australia (16.7\%) and the remaining five were from the UK $(83.3 \%)$. The papers were published between 2010 and 2019, with three papers $(50 \%)$ published in the last 5 years. Two $(33.3 \%)$ papers used mixed methods, one used qualitative $(16.7 \%)$ and the remaining $3(50 \%)$ were discussion papers that presented a case/s where reasonable adjustments were made.

\section{Evidence of reasonable adjustments}

Within the review, individual-level reasonable adjustments were evident prior to and during attendance at the acute hospital. Prior to admission, there was evidence of the person with intellectual disability been accommodated through a preadmission visit, ${ }^{7}{ }^{47}$ being provided with a tour of the hospital/unit ${ }^{47}$ and an introduction to healthcare professionals who would be involved in their care. ${ }^{47}$ At an individual level, there was evidence of a preparatory visit to the individual's home by an anaesthetist and a surgeon to prepare an admission $\operatorname{plan}^{6}$ and conduct a preoperative assessment and other relevant risk assessments. ${ }^{6}$ This visit led to further individual level reasonable adjustments where the person was sedated at home prior to being transferred to hospital for their surgery. ${ }^{6}$ Other preparatory individual level reasonable 


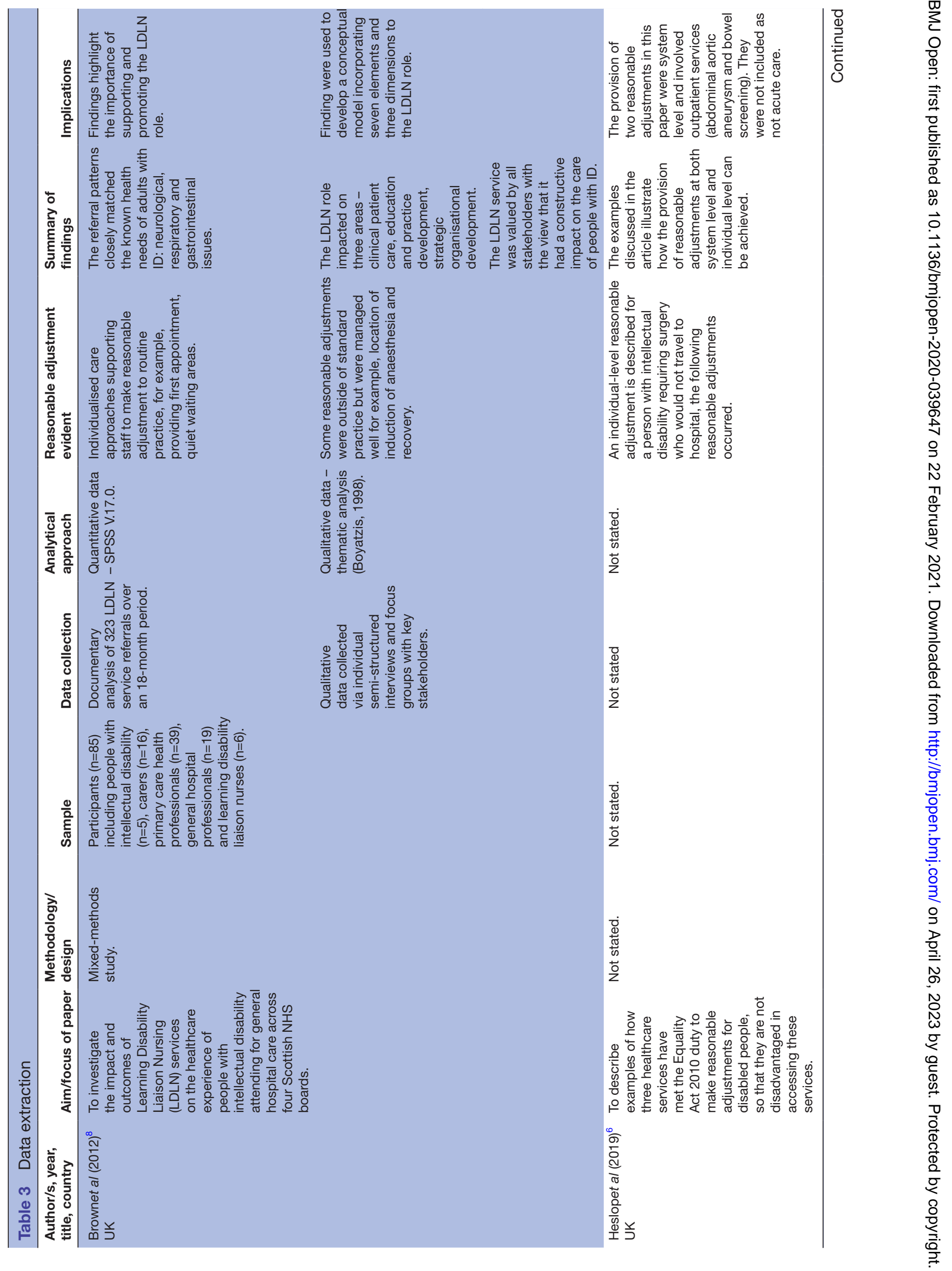




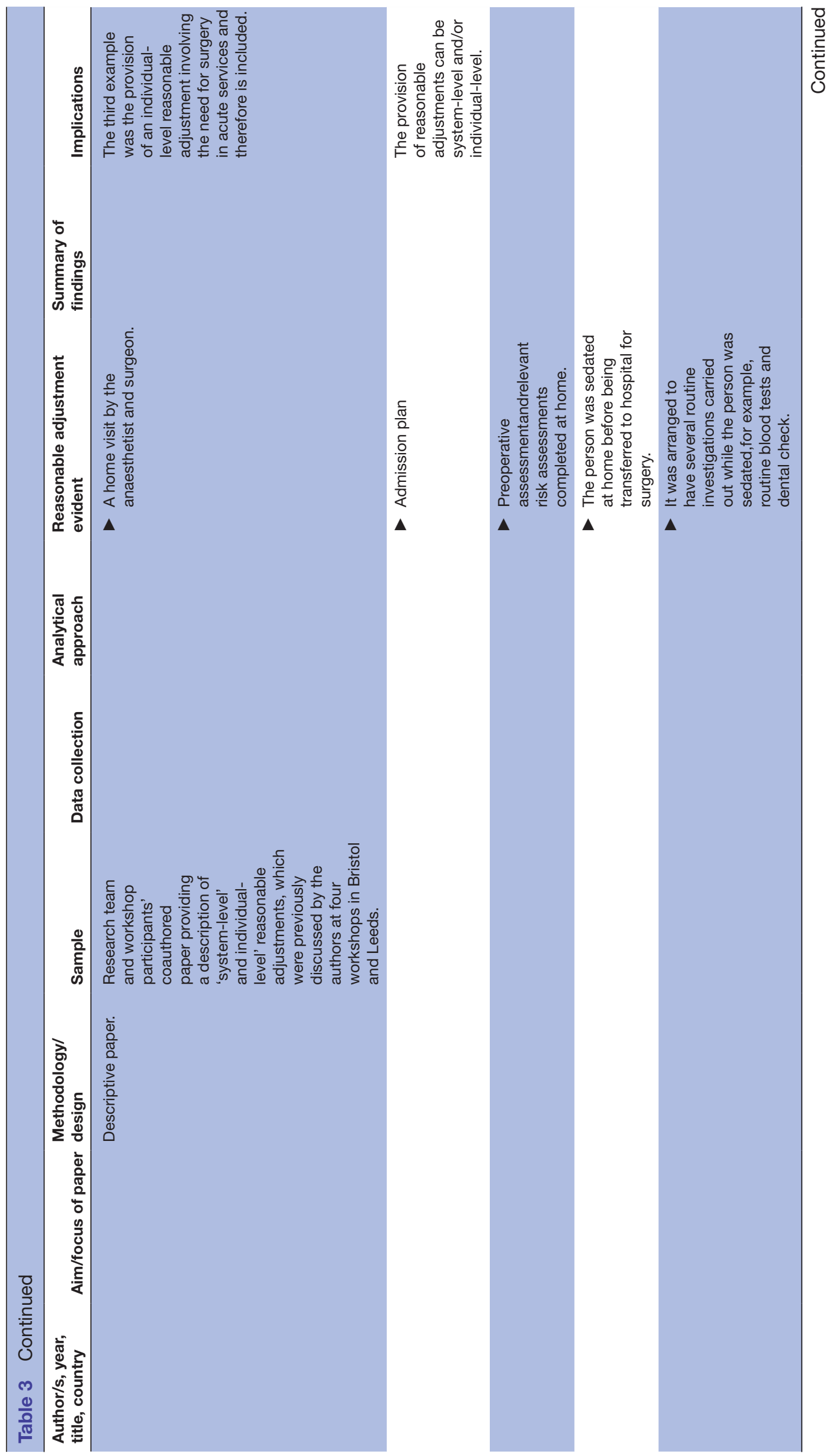




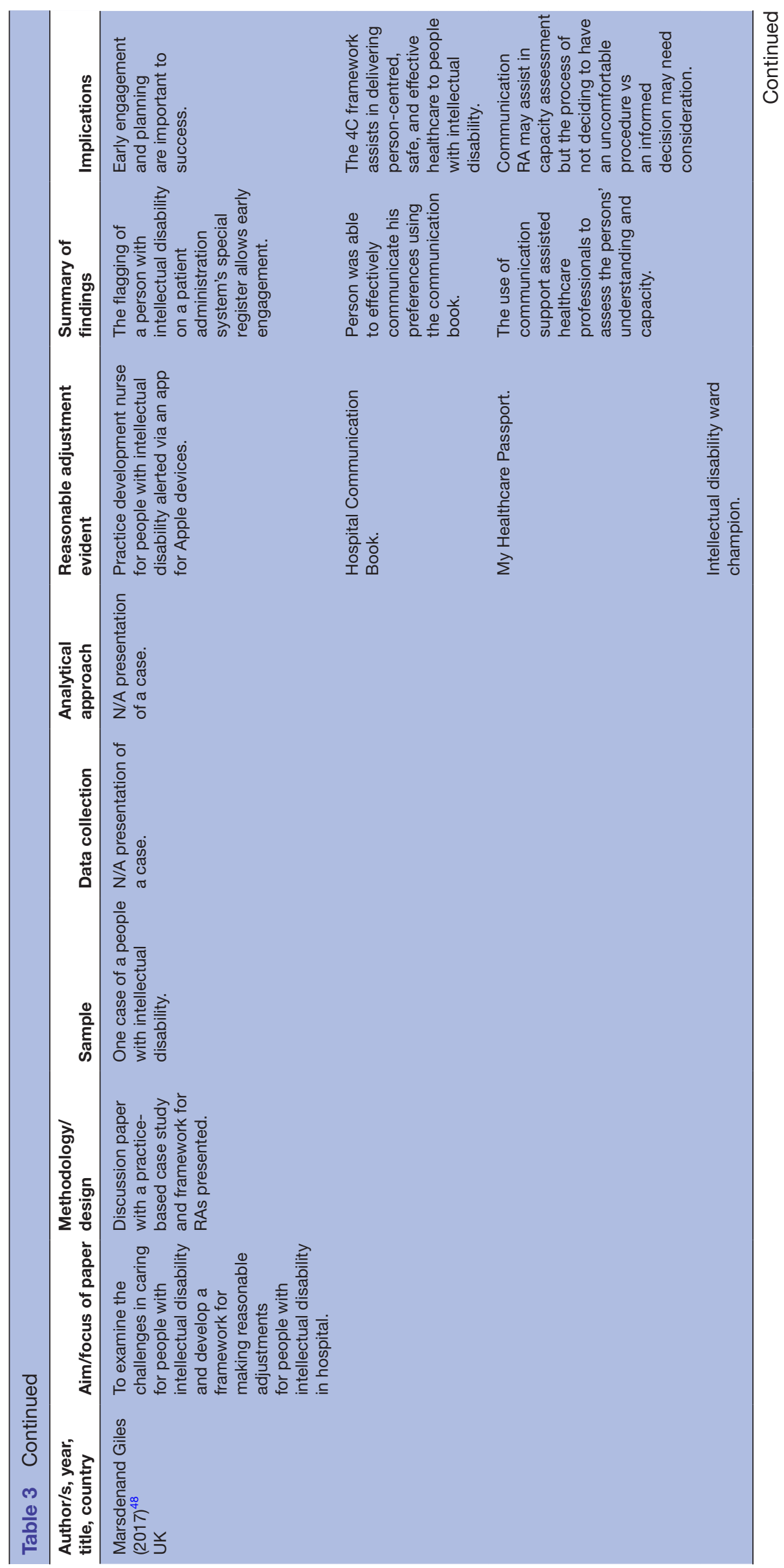

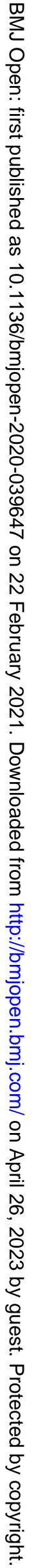




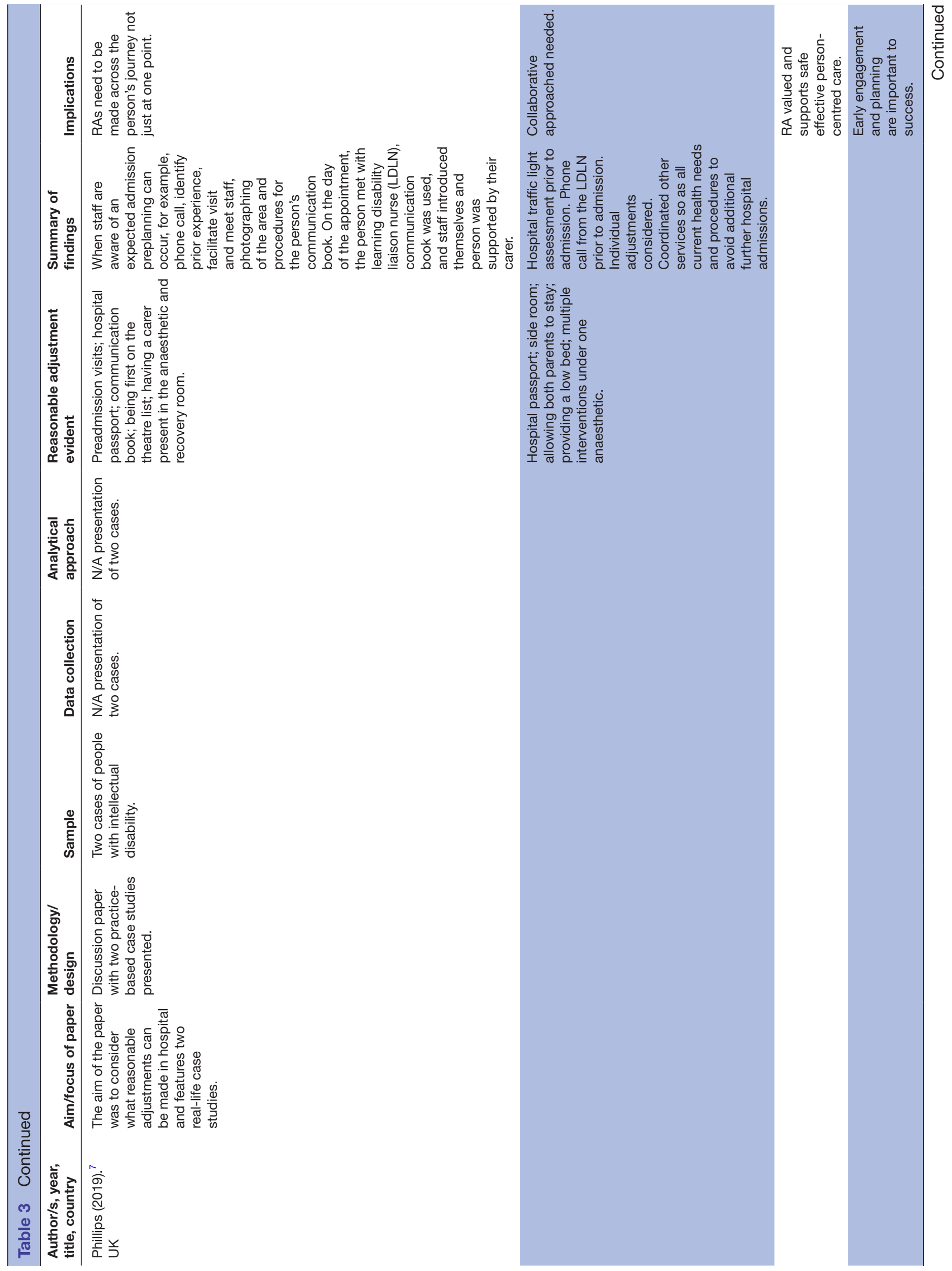




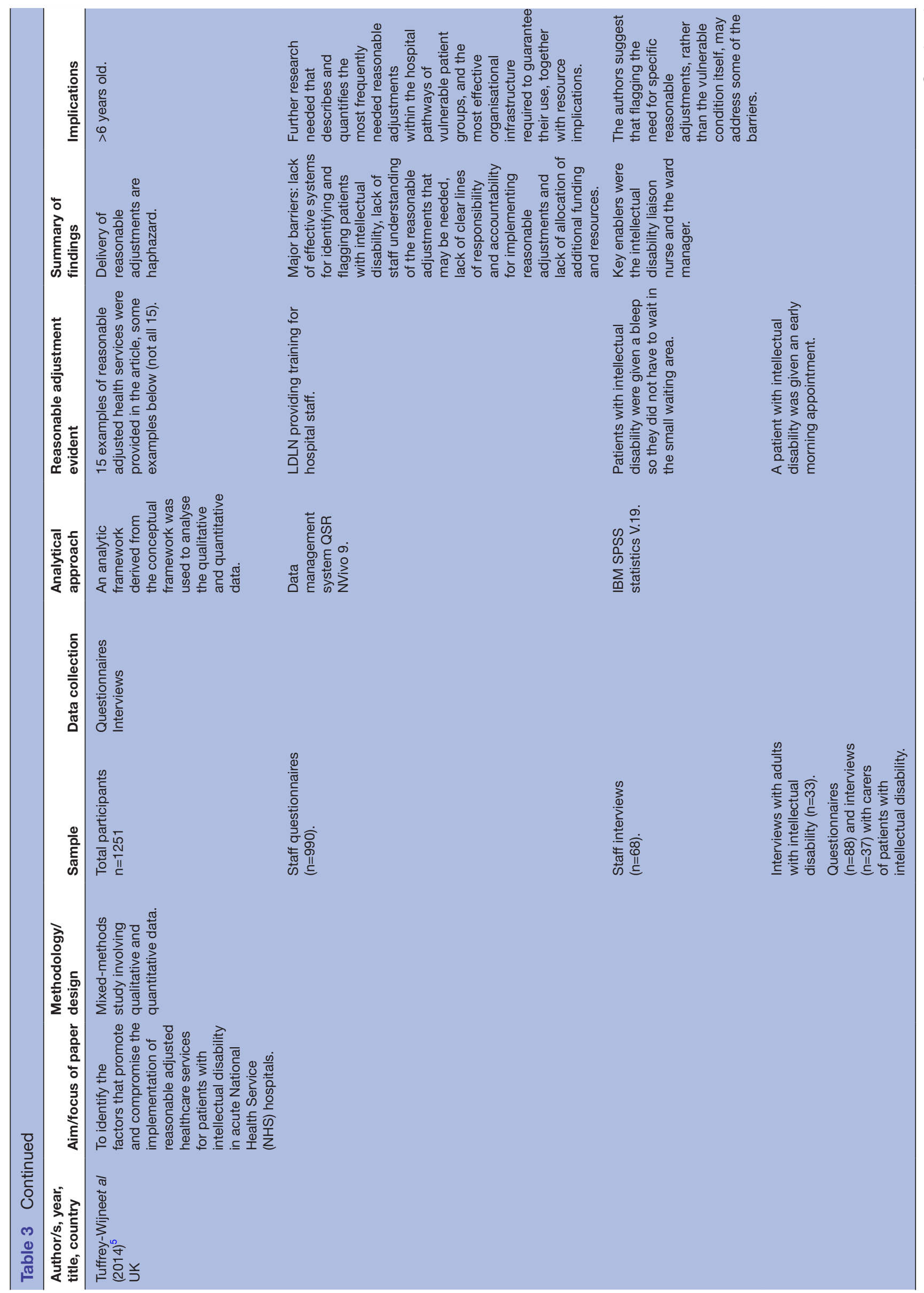




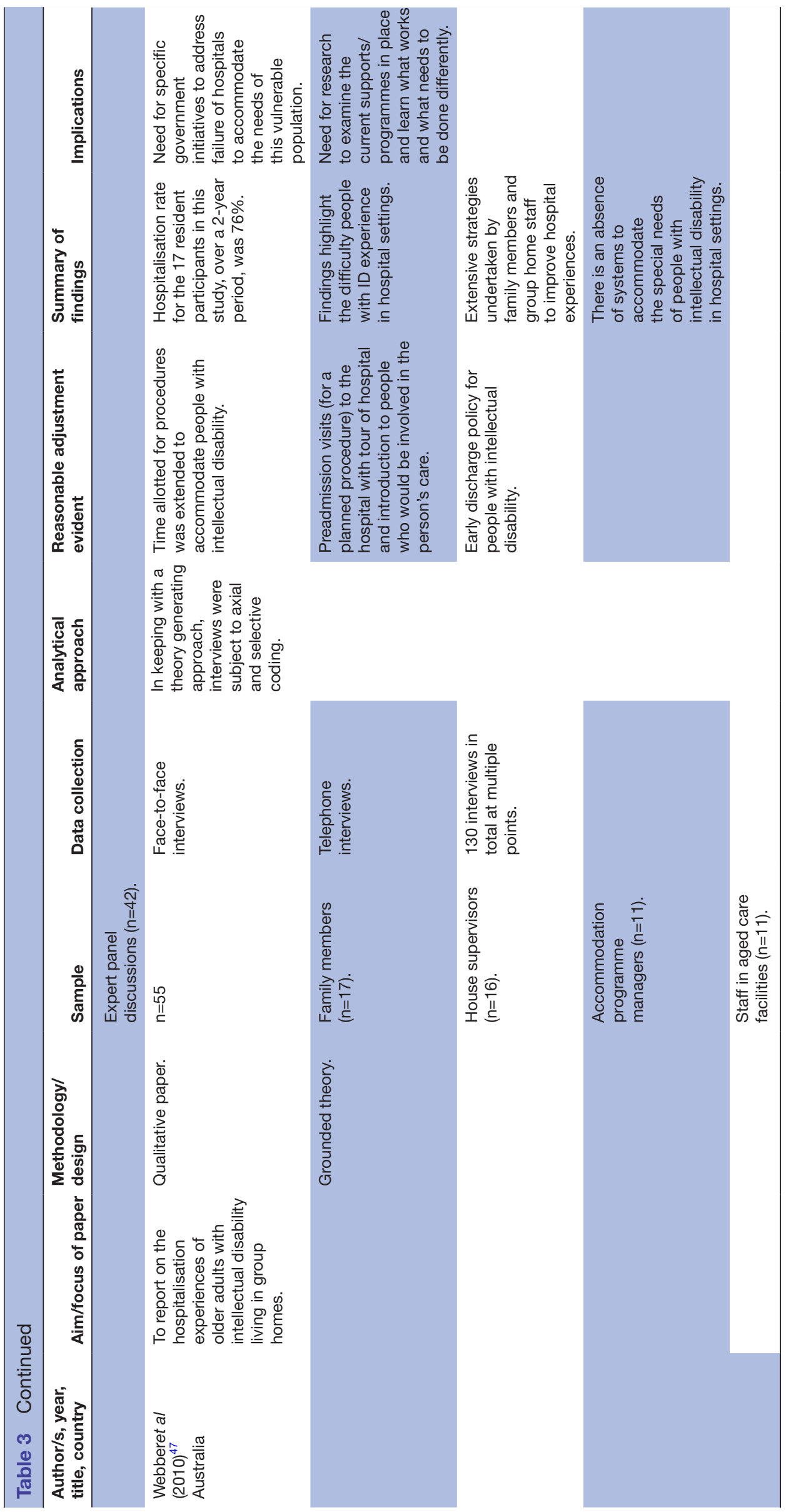


adjustments identified in the review include: modification of appointment times and theatre lists, ${ }^{78}$ extended time allocation for procedures to accommodate communication needs ${ }^{47}$ and/or the facilitation of early morning appointments to avoid crowds and reduce waiting time. ${ }^{34}$

During the hospital visit or stay, many individual-level reasonable adjustments were evident for people with intellectual disability. These adjustments occurred to support the person during the waiting process, communication process and procedure process. Waiting processes were supported through the provision of side rooms, ${ }^{7}$ a quiet area ${ }^{8}$ and a bleep to allow the person the opportunity to move about freely while waiting to be called for their appointment/procedure. ${ }^{34}$ In supporting the communication process, hospital/healthcare passports/ communication books were used. ${ }^{78}$ Within the process of care, individual-level reasonable adjustments were evident where the location of induction of anaesthesia was considered, ${ }^{8}$ location of recovery was considered ${ }^{8}$ and the provision for parents to stay $^{7}$ and parent/carer to be present at the recovery room. ${ }^{8}$ Other interventions noted were the provision of a low bed ${ }^{7}$ and availing of the opportunity for routine investigations to be carried out while the person was sedated, for example, routine blood tests and dental check $^{6}$ or multiple interventions were coordinated while under one anaesthetic. ${ }^{7}$ Early discharge policies were also evident. ${ }^{47}$ It is noteworthy here that a fundamental commonality to all papers that reported evidence of reasonable adjustments in practice was the presence of a person or a healthcare professional who had special expertise in intellectual disability. Within this review, these people were identified as an intellectual disability ward champion, ${ }^{48}$ a practice development nurse for people with intellectual disability and a learning/ intellectual disability liaison nurse who provided training to hospital staff. ${ }^{34}$

\section{DISCUSSION}

This is the first review to specifically explore the evidence regarding the implementation of reasonable adjustments for people with intellectual disability within the acute care setting. Within this review, six papers were synthesised, and the evidence generated suggests that while there are publications regarding the need for reasonable adjustments and the associated enablers/barriers to implementation, there is a paucity of evidence about the actual implementation process or evaluation of reasonable adjustments for people with intellectual disability. The lack of international evidence explicitly reporting on the implementation of reasonable adjustments supporting people with intellectual disability within acute healthcare settings is discerning. Despite international policies advocating to reduce barriers and discrimination, the findings from this review indicate that there is a need for health services and professionals to highlight and make visible their contribution to healthcare for people with intellectual disability. A clear message from the literature is that where reasonable adjustments were made for an individual, positive outcomes were evident for all concerned (table 4 summary of evidence). However, while perceived positive outcomes can be identified, there is little information on the actual implementation and evaluation process, and given the requirement to meet the explicit needs of people with intellectual disability within the care process, there is an opportunity for healthcare professionals to contribute to the body of knowledge and identify any reasonable adjustments they make in practice. The strengths of this scoping review are the systematic nature of the search, the data extraction process, the broad review question and inclusion criteria that allowed for a wide range of papers to be included. The primary limitation of this review was the inclusion of English language papers only and a time restriction of publications from the year 2006 onwards, which was chosen to reflect the publication of the UN Convention. ${ }^{31}$ In addition, the broad terms used in the search strategy may have limited the results, for example, the inclusion of attention deficit hyperactivity disorder and autism in the search may have yielded additional papers. However, the broad terms used such as 'learning disability' and 'developmental disability' may have incorporated these results. Key to discussing the findings of this review is considering the wider literature and implications for policymakers, practitioners and researchers. While reasonable adjustments are positive measures that can address health inequalities, they need to be supported at an organisational, system and individual level spanning the planning, delivery and evaluation stages. ${ }^{6}$

It is evident in the literature that one of the major barriers to the provision of reasonable adjusted care is the lack of systematic identification and flagging of people in the system, ${ }^{49}$ which focuses on the adjustment needed rather than the disability or condition. ${ }^{50}{ }^{51}$ Identifying and flagging the 'need for reasonable adjusted care' rather than flagging the 'individual with a disability or condition' may be a more appropriate action for healthcare professionals in the provision of individualised effective safe care for vulnerable people. ${ }^{51}$ Such an approach has the potential to positively influence healthcare outcomes for other vulnerable populations, for example, people with adaptive functioning resulting from head injuries, dementia or severe mental health illness. ${ }^{52}$

While a robust identification system would go some way to addressing the lack of implementation of reasonable adjusted care, at a practical level, it must also be acknowledged that people with intellectual disability require very specific supports, for example, extended consultation times or prehospital visits. ${ }^{43} 53$ It is evident within the literature that healthcare professionals often lack specific knowledge and understanding of intellectual disability and have limited experience of working with this population. ${ }^{55}$ This lack of knowledge and inexperience can give rise to negative attitudes ${ }^{56}$ and misconceptions ${ }^{5859}$ that often lead to fear of caring for people with intellectual disability. ${ }^{60} 61$ 
Table 4 Summary of evidence

\begin{tabular}{|c|c|}
\hline Author & Reasonable adjustment evident \\
\hline Brown et al ${ }^{8}$ & $\begin{array}{l}\text { Individualised care approaches supporting staff to make reasonable } \\
\text { adjustment to routine practice, for example, providing first } \\
\text { appointment and quiet waiting areas. } \\
\text { Some reasonable adjustments were outside of standard practice } \\
\text { and managed well, for example, location of induction of anaesthesi } \\
\text { and recovery. }\end{array}$ \\
\hline Heslop et a ${ }^{6}$ & $\begin{array}{l}\text { A home visit by the anaesthetist and surgeon. } \\
\text { Admission plan. } \\
\text { Preoperative assessment and relevant risk assessments completed } \\
\text { at home. } \\
\text { Facilitated patient sedation outside standard practice (ie, at home), } \\
\text { prior to transfer to hospital. } \\
\text { It was arranged to have several routine investigations carried out } \\
\text { while the person was sedated, for example, routine blood tests and } \\
\text { dental check. }\end{array}$ \\
\hline $\begin{array}{l}\text { Marsden and } \\
\text { Giles }^{48}\end{array}$ & $\begin{array}{l}\text { Practice development nurse for people with intellectual disability } \\
\text { alerted via a smartphone app for Apple devices. } \\
\text { - Hospital Communication Book. } \\
\text { - My Healthcare Passport. } \\
\text { Intellectual disability ward champion. }\end{array}$ \\
\hline Phillips $^{7}$ & - Preadmission visit. \\
\hline
\end{tabular}

Leadership of reasonable adjustment

information sharing, assessment, providing advice, capacity and consent issues, discharge planning, risk management and client/carer support.

Intellectual disability nurses lead and coordinated the home visit by the consultant anaesthetist and surgeon and supported the development of an admission plan with the person with intellectual disability, their family and carers including a preoperative assessment and relevant risk assessments.

Practice development nurse for people with intellectual disability within the hospital. Collaborated with ward nurses, doctor and care workers to support communication and capacity assessment.

Intellectual disability liaison nurse coordinated care with ward staff and communication support in conjunction with a speech and language therapist in case study one. In case study two, the learning disability liaison nurse coordinated care across several areas to provide a combined healthcare appointment of dental, audiology, cardiac and anaesthesiology.

- Hospital passport.

- Communication book.

- Being first on the theatre list.

- Having a carer present in the anaesthetic and recovery room.

- Side room made available.

- Allowing both parents to stay.

- Providing a low bed.

- Multiple interventions under one anaesthetic.

Tuffrey-Wijne et $a l^{51}$
- LDLN providing training for hospital staff.

- Providing patient-held information documents for people with intellectual disability to record key information for the benefit of hospital staff, including likes and dislikes.

- Patients with intellectual disability and their carers attended outpatient appointments were provided with a bleep so they did not have to wait in the small waiting area.

- Facilitated patient sedation outside standard practice (patient sedated in the car park prior to entry to hospital with his consent and his family's support).

- A preadmission visits organised for people with intellectual disability to look around the ward area.

- A patient who has difficulties coping with tests and treatments had several other necessary tests and treatments carried out involving a range of different clinicians while under general anaesthetic for dental surgery.
Intellectual disability liaison nurses provided training for hospital staff. 


\begin{tabular}{|c|c|c|}
\hline \multirow[t]{6}{*}{ Author } & Reasonable adjustment evident & Leadership of reasonable adjustment \\
\hline & Carers were offered food, a bed and a parking permit. & \\
\hline & $\begin{array}{l}\text { No unnecessary ward transfers/changes allowing patients with } \\
\text { intellectual disability who only need a few days in hospital to stay } \\
\text { on the ward rather than be moved to a different ward. }\end{array}$ & \\
\hline & $\begin{array}{l}\text { Patients with intellectual disability with significant care needs are } \\
\text { allocated additional care staff. }\end{array}$ & \\
\hline & $\begin{array}{l}\text { A patient with intellectual disability who found it difficult to cope } \\
\text { with a busy ward environment who required treatment on a day } \\
\text { surgery ward where no separate room were available, was given } \\
\text { a bed by the window with the curtains pulled round and staff } \\
\text { informed the patient exactly what to expect and they coped well } \\
\text { with the treatment and environment. }\end{array}$ & \\
\hline & $\begin{array}{l}\text { The carers of patients with intellectual disability are invited to attend } \\
\text { the consultant's ward rounds. }\end{array}$ & \\
\hline \multirow[t]{2}{*}{ Webber et al ${ }^{47}$} & $\begin{array}{l}\text { Time allotted for appointment extended to accommodate people } \\
\text { with intellectual disability. }\end{array}$ & $\begin{array}{l}\text { No specialised intellectual disability nurses } \\
\text { and carers perceived staff in the acute } \\
\text { setting to be generally uncomfortable with } \\
\text { or indifferent to the needs of people with } \\
\text { intellectual disability. Where there were } \\
\text { positive experiences, this occurred where } \\
\text { there were clear policies, resources and } \\
\text { systems in place to address the needs of } \\
\text { people with intellectual disability. }\end{array}$ \\
\hline & Early discharge policy for people with intellectual disability. & \\
\hline
\end{tabular}

The lack of experience ${ }^{39} 62$ and contact with people with intellectual disability ${ }^{6163}$ is further compounded by communication issues when the healthcare professional encounters a person with intellectual disability. ${ }^{394}$ Lack of knowledge and understanding of intellectual disability ${ }^{393}$ is reinforced by limited education on intellectual disability during undergraduate and postgraduate education. ${ }^{65} 66$ This raises the issue for healthcare educators to develop and deliver educational programmes that address intellectual disability and reasonable adjustments within healthcare delivery. One approach to addressing this educational deficit would be the meaningful inclusion of people with intellectual disability and their advocates in healthcare professional education design, delivery and evaluation. ${ }^{67-69}$ Such an approach holds the possibility of benefiting both the person with the disability and the learner ${ }^{70}$ in terms of increased knowledge and understanding and in challenging stereotypes. ${ }^{71} 72$
These issues are pertinent given the changing landscape of intellectual disability services in recent years with a shift from institutional care to a community care model. ${ }^{73} 74$ Thereby, people with intellectual disability now access care through mainstream health services, and this has impacted on issues such as health disparities, ${ }^{38}$ health inequalities ${ }^{75}$ and health outcomes. ${ }^{76}$ Within this changing landscape of service provision, ${ }^{7778}$ it is essential that healthcare professionals can anticipate and support the holistic needs of people with intellectual disability. ${ }^{6}$ This calls for a care approach that is truly person centred and tailor made as opposed to the one-size-fits-all approach that has served this population poorly to date. ${ }^{779}$

It is abundantly clear that reasonably adjusted care is a necessary component of a modern healthcare service for people with intellectual disability. This review highlights that the key to successful care provision for people with intellectual disability in acute healthcare services lies 
clearly with the presence of skilled, knowledgeable and experienced professionals with a background in intellectual disability. There is a growing body of evidence that this expertise can be provided through the provision of a liaison intellectual disability nursing role within the acute care setting. ${ }^{34} 76$ The intellectual disability nurse has a unique transferrable skill set that could positively impact on care in the acute setting for people with intellectual disability and support the reshaping of healthcare provision. ${ }^{80-84}$ It is clear within this review that when liaison did occur it was positively received, evaluated and successfully contributed to care. ${ }^{85} 86$ Such a means of collaborative working could assist in addressing some of the knowledge deficits and education needs described. ${ }^{76} 87$ Collaborative working has the potential to reduce fragmentation of services and improve continuity and consistency of care, thus increasing patient safety, reducing risk and improving patient outcomes. ${ }^{88} 89$

Thereby, based on the evidence, we advocate for the implementation of reasonable adjustments to promote equitable and optimum healthcare and to avoid compounding health inequalities for people with intellectual disability. Systematic identification, monitoring and recording of reasonably adjusted care is crucial. Healthcare managers working collaboratively with liaison intellectual disability nurses and other stakeholders can take the lead to promote and support the identification and implementation of reasonable adjustments throughout the entire acute hospital care experience, ensuring healthcare equity and improved healthcare outcomes for people with intellectual disability. ${ }^{6} 763890$

\section{CONCLUSION}

It is important that the healthcare needs of people with intellectual disability are met across the continuum of healthcare provision, including acute care settings. ${ }^{6}$ However, people with intellectual disability are experiencing hardship accessing and receiving acute care, and international evidence regarding health inequalities experienced by this population is abundant. ${ }^{38}$ To address such inequalities, reasonable adjustments need to be addressed and implemented. They should be anticipatory and person centred, meaning that measures are taken in advance to ensure that each person's individual needs are met, thus enhancing care for vulnerable people such as people with intellectual disability. ${ }^{34}$ As evidenced in this review, the data are scarce, and it appears that research in this area remains largely at the point of identifying what needs to be adjusted rather than reporting evidence of actual implementation. However, the research does highlight the value of the liaison intellectual disability nursing role and service user input in influencing the provision of individualised, equitable and accessible healthcare. In support of a gold standard of healthcare that aligns with international policy, it is imperative that service providers, healthcare professionals and service users actively engage to identify, develop and implement reasonable adjustments within acute healthcare settings.

Contributors $\mathrm{OD}$ initiated the discussion with the other authors, and all authors developed the search process and criteria. OD conducted the search and exporting of results to Endnote. Results were screened by paired reviewers independently $(\mathrm{OD} / \mathrm{TH}$ and $\mathrm{OD} / \mathrm{MM})$ and data extracted by each reviewer and verified by a second reviewer (OD, MM and $\mathrm{TH}$ ). All authors contributed to the data analysis and synthesis and provided critical feedback and helped shape the review, analysis and manuscript. OD took the overall lead in writing the manuscript, and all authors agreed on the final submission.

Funding The authors have not declared a specific grant for this research from any funding agency in the public, commercial or not-for-profit sectors.

Competing interests None declared.

Patient consent for publication Not required.

Provenance and peer review Not commissioned; externally peer reviewed.

Data availability statement All data relevant to the study are included in the article.

Open access This is an open access article distributed in accordance with the Creative Commons Attribution Non Commercial (CC BY-NC 4.0) license, which permits others to distribute, remix, adapt, build upon this work non-commercially, and license their derivative works on different terms, provided the original work is properly cited, appropriate credit is given, any changes made indicated, and the use is non-commercial. See: http://creativecommons.org/licenses/by-nc/4.0/.

\section{ORCID iD}

Owen Doody http://orcid.org/0000-0002-3708-1647

\section{REFERENCES}

1 World Health Organisation. Definition: intellectual disability. Available: http://www.euro.who.int/en/health-topics/noncommunicablediseases/mental-health/news/news/2010/15/childrens-right-tofamily-life/definition-intellectual-disability

2 Oliver M. The politics of disablement. London: Macmillan Education, 1990.

3 Salvador-Carulla L, Saxena S. Intellectual disability: between disability and clinical nosology. Lancet 2009;374:1798-9.

4 World Health Organization. Atlas: Global resources for persons with intellectual disabilities. Geneva, Switzerland: World Health Organization Press, 2007.

5 Tuffrey-Wijne I, Goulding L, Giatras N, et al. The barriers to and enablers of providing reasonably adjusted health services to people with intellectual disabilities in acute hospitals: evidence from a mixed-methods study. BMJ Open 2014;4:e004606.

6 Heslop P, Turner S, Read S, et al. Implementing reasonable adjustments for-disabled people in healthcare services. Nurs Stand 2019;34:29-34.

7 Phillips L. Learning disabilities: making reasonable adjustments in hospital. Nurs Times 2019;115:38-42.

8 Brown M, MacArthur J, McKechanie A, et al. Learning disability liaison nursing services in south-east Scotland: a mixed-methods impact and outcome study. J Intellect Disabil Res 2012;56:1161-74.

9 Emerson E, Hatton C, Baines S, et al. The physical health of British adults with intellectual disability: cross sectional study. Int $J$ Equity Health 2016;15:11.

10 Young-Southward G, Rydzewska E, Philo C, et al. Physical and mental health of young people with and without intellectual disabilities: cross-sectional analysis of a whole country population. J Intellect Disabil Res 2017;61:984-93.

11 Smith L, Dowse L. Complexity and disability: Drawing from a complexity approach to think through disability at the intersections. In: Ellis K, Garland-Thomson R, Kent M, et al, eds. Interdisciplinary approaches to disability: looking towards the future. New York: Routledge Taylor Francis Group, 2019: Vol 2. 123-30.

12 Wark S, Kingstone M. The complexity of lifelong comorbidities with severe intellectual disability. J Intellect Dev Dis 2019;44:431-8.

13 Muskens JB, Velders FP, Staal WG. Medical comorbidities in children and adolescents with autism spectrum disorders and attention deficit hyperactivity disorders: a systematic review. Eur Child Adoles Psy 2017;26:1093-103.

14 Startin CM, D'Souza H, Ball G, et al. Health comorbidities and cognitive abilities across the lifespan in Down syndrome. J Neurodev Disord 2020;12:4. 
15 Chauhan U, Courtenay K, Hoghton M. Physical health in people with intellectual disabilities. In: Bhaumik S, Alexande R, eds. Oxford textbook of the psychiatry of intellectual disability. Oxford: Oxford University Press, 2020.

16 Stancliffe RJ, Durvasula S, Wilson NJ. Treatment engagement and people with intellectual disability. In: Hadler A, Sutton S, Osterberg L, eds. The Wiley Handbook of healthcare treatment engagement: theory, research, and clinical practice. Hoboken: Wiley Blackwell, 2020: 381-98.

17 O'Dwyer M, Peklar J, McCallion P, et al. Factors associated with polypharmacy and excessive polypharmacy in older people with intellectual disability differ from the general population: a cross-sectional observational nationwide study. BMJ Open 2016;6:e010505.

18 Selph C, Cosca B. Less is more: preventing polypharmacy in individuals with intellectual disabilities. Impact 2016;29:28-9.

19 Heslop P, Blair PS, Fleming P, et al. The confidential inquiry into premature deaths of people with intellectual disabilities in the UK: a population-based study. Lancet 2014;383:889-95.

20 O'Leary L, Cooper S-A, Hughes-McCormack L. Early death and causes of death of people with intellectual disabilities: a systematic review. J Appl Res Intellect Disabil 2018;31:325-42.

21 St. John BM, Hladik E, Romaniak HC, et al. Understanding health disparities for individuals with intellectual disability using photovoice. Scand J Occup Ther 2018;25:371-81.

22 Sabatello M. Precision medicine, health disparities, and ethics: the case for disability inclusion. Genet Med 2018;20:397-9.

23 Slater $\mathrm{H}$, Baxter $\mathrm{H}$, Kerr M. Barriers to health care services and the role of the physician. In: Prasher VP, Janicki MP, eds. Physical health of adults with intellectual and developmental disabilities. 2nd edn. Cham, Switzerland: Springer, 2019: 381-96.

24 Durbin A, Sirotich F, Lunsky Y, et al. Unmet needs of adults in community mental health care with and without intellectual and developmental disabilities: a cross-sectional study. Community Ment Health J 2017;53:15-26.

25 Mencap. Death by indifference: following up the treat me right! report. London: Mencap, 2007.

26 Mencap. Death by indifference. 74 deaths and counting: a progress report 5 years on. London: Mencap, 2012.

27 Crnic KA, Neece CL, McIntyre LL, et al. Intellectual disability and developmental risk: promoting intervention to improve child and family well-being. Child Dev 2017;88:436-45.

28 Michael J. Healthcare for all: report of the independent inquiry into access to healthcare for people with learning disabilities. London: Department of Health, 2008. https://webarchive.nationalarchives.gov. uk/20130105064250/http://www.dh.gov.uk/en/Publicationsandstati stics/Publications/PublicationsPolicyAndGuidance/DH_099255

29 Office of the Surgeon General, National Institute of Child Health and Human Development, Centers for Disease Control and Prevention. Closing the gap: A National blueprint to improve the health of persons with mental retardation: Report of the Surgeon General's Conference on Health Disparities and Mental Retardation. Washington, DC: United States Department of Health and Human Services, 2002. http://www.ncbi.nlm.nih.gov/books/NBK44354/

30 Glover G, Emerson E, Baines S. NHS data gaps for learning disabilities. The information the NHS needs to monitor the health and healthcare of people with learning disabilities. London: Improving Health and Lives Learning Disabilities Observatory, 2011. http:// webarchive.nationalarchives.gov.uk/20160704155744/http://www. improvinghealthandlives.org.uk/uploads/doc/vid_11422_IHAL201106-NHSDataGaps.pdf

31 United Nations. Convention on the rights of persons with disabilities. New York: United Nations, 2006.

32 United Kingdom Government. Equality act. London: The Stationery Office, 2010.

33 Equality and Human Rights Commission. Being disabled in Britain: a journey less equal. London: Equality and Human Rights Commission, 2017. https://www.equalityhumanrights.com/sites/default/files/beingdisabled-in-britain.pdf

34 Sakellariou D, Rotarou ES. The effects of neoliberal policies on access to healthcare for people with disabilities. Int J Equity Health 2017; $16: 199$

35 lacono T, Bigby C, Unsworth C, et al. A systematic review of hospital experiences of people with intellectual disability. BMC Health Serv Res 2014;14:505.

36 Hatton C, Roberts H, Baines S. Reasonable adjustments for people with learning disabilities in England 2010: a national survey of NHS trusts. Lancaster: IHAL Improving Health and Lives Learning Disabilities Observatory, 2011.

37 Atkinson S. Hospital passports not being used in learning disability care. Learn Disabil Pract 2016;19:11.
38 Northway R, Rees S, Davies M, et al. Hospital passports, patient safety and person-centred care: a review of documents currently used for people with intellectual disabilities in the UK. J Clin Nurs 2017;26:5160-8.

39 Lewis P, Gaffney RJ, Wilson NJ. A narrative review of acute care nurses' experiences nursing patients with intellectual disability: underprepared, communication barriers and ambiguity about the role of caregivers. J Clin Nurs 2017;26:1473-84.

40 Louw JM, Marcus TS, Hugo JFM. Patient- or person-centred practice in medicine? - a review of concepts. Afr. j. prim. health care fam. med. 2017;9:e1-7.

41 Ellis P. Person-centred assessment and practice. In: Ellis P, Standing $\mathrm{M}$, Roberts S, eds. Patient assessment and care planning in nursing. 3rd edn. London: Learning Matters, 2020: 6-20.

42 Hakobyan L, Nieboer AP, Finkenflügel $\mathrm{H}$, et al. The significance of person-centered care for satisfaction with care and well-being among informal caregivers of persons with severe intellectual disability. J Policy Pract Intel 2020;17:31-42.

43 lacono T, Bigby C. The health inequalities of people with intellectual and developmental disabilities: strategies for change. In: Liamputtong P, ed. Public health: local and global perspectives. Port Melbourne: Cambridge University Press, 2016: 294-312.

44 Munn Z, Peters MDJ, Stern C, et al. Systematic review or scoping review? Guidance for authors when choosing between a systematic or scoping review approach. BMC Med Res Methodol 2018;18:143.

45 Peters MDJ, Godfrey C, Mclnerney P. Chapter 11: Scoping reviews. In: Aromataris E, Munn Z, eds. Joanna Briggs institute reviewer's manual. Adelaide, Australia: Joanna Briggs Institute, 2020. https:// reviewersmanual.joannabriggs.org/

46 Tricco AC, Lillie E, Zarin W, et al. PRISMA extension for scoping reviews (PRISMA-ScR): checklist and explanation. Ann Intern Med 2018;169:467-73.

47 Webber R, Bowers B, Bigby C. Hospital experiences of older people with intellectual disability: responses of group home staff and family members. J Intellect Dev Disabil 2010;35:155-64.

48 Marsden D, Giles R. The 4C framework for making reasonable adjustments for people with learning disabilities. Nurs Stand 2017;31:45-53

49 Puccetti L, Nerattini M, Quercioli C, et al. Model of a health program for people with disability: flagging the need, not the disability. $J$ Intellect Dev Disabil 2020;45:133-8.

50 Kenten C, Wray J, Gibson F. To FLAG or not to FLAG: identification of children and young people with learning disabilities in English hospitals. J App/ Res Intellect 2019;32:1176-83. doi:10.1111/ jar. 12608

51 Tuffrey-Wijne I, Giatras N, Goulding L, et al. Identifying the factors affecting the implementation of strategies to promote a safer environment for patients with learning disabilities in NHS hospitals: a mixed-methods study. Health Serv Deliv Res 2013;1:1-224.

52 Atkinson D, Boulter P, Pointu A, et al. Learning disability nursing: how to refocus the profession. Learn Disabil Pract 2010;13:18-21.

53 Carey IM, Shah SM, Hosking FJ, et al. Health characteristics and consultation patterns of people with intellectual disability: a crosssectional database study in English general practice. $\mathrm{Br} J$ Gen Pract 2016;66:e264-70.

54 Finlayson J, De Amicis L, Gallacher S, et al. Reasonable adjustments to provide equitable and inclusive assessment, screening and treatment of osteoporosis for adults with intellectual disabilities: a feasibility study. J Appl Res Intellect Disabil 2019;32:300-12.

55 Emerson E, Baines S, Allerton L. Health inequalities and people with learning disabilities in the UK. Cambridge: Improving Health and Lives Learning Disabilities Observatory, 2012.

56 Morin D, Valois P, Crocker AG, et al. Attitudes of health care professionals toward people with intellectual disability: a comparison with the general population. J Intellect Disabil Res 2018;62:746-58.

57 Ditchman N, Kosyluk K, Lee EJ, et al. How stigma affects the lives of people with intellectual disabilities: an overview. In: Scior K, Werner $\mathrm{S}$, eds. Intellectual disability and stigma: stepping out of the margins. London: Palgrave Macmillan, 2016pp.: 31-47.

58 Breau G, Baumbusch J, Thorne S. Primary care providers' attitudes towards individuals with intellectual disability: Associations with experience and demographics. $J$ Intellect Disabil2019;1744629519860029.

59 Purty S, Singh AR. Awareness on different aspects of intellectual disability among caregivers. Int J Res Soc Sci 2018;8:530-7.

60 Desroches ML, Sethares KA, Curtin C, et al. Nurses' attitudes and emotions toward caring for adults with intellectual disabilities: Results of a cross-sectional, correlational-predictive research study. J Appl Res Intellect Disabil 2019;32:1501-13.

61 Pelleboer-Gunnink HA, Van Oorsouw WMWJ, Van Weeghel J, et al. Mainstream health professionals' stigmatising attitudes towards 
people with intellectual disabilities: a systematic review. $J$ Intellect Disabil Res 2017;61:411-34.

62 Brown M, Taggart L, Karatzias T, et al. Improving diabetes care for people with intellectual disabilities: a qualitative study exploring the perceptions and experiences of professionals in diabetes and intellectual disability services. J Intellect Disabil Res 2017;61:435-49.

63 Kersten MCO, Taminiau EF, Schuurman MIM, et al. How to improve sharing and application of knowledge in care and support for people with intellectual disabilities? A systematic review. J Intellect Disabil Res 2018;62:496-520.

64 Appelgren M, Bahtsevani C, Persson K, et al. Nurses' experiences of caring for patients with intellectual developmental disorders: a systematic review using a meta-ethnographic approach. BMC Nurs 2018;17:51.

65 Trollor JN, Eagleson C, Turner B, et al. Intellectual disability content within pre-registration nursing curriculum: how is it taught? Nurse Educ Today 2018;69:48-52.

66 Furst MAC, Salvador-Carulla L. Intellectual disability in Australian nursing education: experiences in NSW and Tasmania. $J$ Intellect Dev Disabil 2019;44:357-66.

67 Archer T, Boyd K, Moores G. Tell us more - People with developmental disability share experiences to enhance health care education: An exploratory study. J Dev Disabil 2018:23:71-9.

68 É M, Garcia V, Boucher N. Co-Developing interprofessional course content with people with disabilities. Can J Dis Stud 2018;7:146-52.

69 Watkins LV, Colgate R. Improving healthcare for people with intellectual disabilities: the development of an evidence-based teaching programme. AMHID 2016;10:333-41.

70 Smith P, Ooms A, Marks-Maran D. Active involvement of learning disabilities service users in the development and delivery of a teaching session to pre-registration nurses: Students' perspectives. Nurse Educ Pract 2016;16:111-8.

71 Felton A, Cook J, Anthony R. Evaluating a co-facilitation approach to service user and carer involvement in undergraduate nurse education. Nurs Stand 2018;32:47-54.

72 Warne T, McAndrew S. Using patient experience in nurse education. Basingstoke: Palgrave Macmillan, 2004.

73 Doody O, Murphy F, Lyons R, et al. Development of nursing quality care process metrics and indicators for intellectual disability services: a literature review and modified Delphi consensus study. BMC Health Serv Res 2019;19:909.

74 Doody O. Families' views on their relatives with intellectual disability moving from a long-stay psychiatric institution to a communitybased intellectual disability service: an Irish context. $\mathrm{Br} J$ Learn Disabil 2012;40:46-54.

75 World Health Organization. WHO global disability action plan 20142021: better health for all people with disability. Geneva, Switzerland: World Health Organization Press, 2015.

76 Oulton K, Wray J, Hassiotis A, et al. Learning disability nurse provision in children's hospitals: hospital staff perceptions of whether it makes a difference. BMC Pediatr 2019;19:192.
77 McCarron M, Sheerin F, Roche L. Shaping the future of intellectual disability nursing in Ireland. Dublin: Health Services Executive, 2018.

78 Byers V. The challenges of leading change in health-care delivery from the front-line. J Nurs Manag 2017;25:449-56.

79 Taggart L, Truesdale M, Dunkley A, et al. Health promotion and wellness initiatives targeting chronic disease prevention and management for adults with intellectual and developmental disabilities: recent advancements in type 2 diabetes. Curr Dev Disord Rep 2018;5:132-42.

80 Doody O, Slevin E, Taggart L. Focus group interviews examining the contribution of intellectual disability clinical nurse specialists in Ireland. J Clin Nurs 2017;26:2964-75.

81 Wilson NJ, Wiese M, Lewis P, et al. Nurses working in intellectual disability-specific settings talk about the uniqueness of their role: a qualitative study. J Adv Nurs 2019;75:812-22.

82 O'Reilly K, Lewis P, Wiese M, et al. An exploration of the practice, policy and legislative issues of the specialist area of nursing people with intellectual disability: a scoping review. Nurs Inq 2018;25:e12258.

83 Jaques $\mathrm{H}$, Lewis $\mathrm{P}$, O'Reilly $\mathrm{K}$, et al. Understanding the contemporary role of the intellectual disability nurse: a review of the literature. $J$ Clin Nurs 2018;27:3858-71.

84 Doody O, Slevin E, Taggart L. The development of clinical nurse specialists (CNSs) in intellectual disability nursing in Ireland. $J$ Intellect Disabil 2012;16:163-72.

85 Brown M, Chouliara Z, MacArthur J, et al. The perspectives of stakeholders of intellectual disability liaison nurses: a model of compassionate, person-centred care. J Clin Nurs 2016;25:972-82.

86 Finlayson J, Dick J, Neil J, et al. An evaluation of vision champion training for community learning disability healthcare professionals. Learn Disabil Pract 2017;20:28-34.

87 Bailey M, Doody O, Lyons R. Surveying community nursing support for persons with an intellectual disability and palliative care needs. $\mathrm{Br}$ $J$ Learn Disabil 2016;44:24-34.

88 Watkins L, O'Dwyer M, Kerr M, et al. Quality improvement in the management of people with epilepsy and intellectual disability: the development of clinical guidance. Expert Opin Pharmaco 2020;21:173-81.

89 Mimmo L, Harrison R, Hinchcliff R. Patient safety vulnerabilities for children with intellectual disability in hospital: a systematic review and narrative synthesis. BMJ Paediatr Open 2018;2:e000201.

90 MacArthur J, Brown M, McKechanie A, et al. Making reasonable and achievable adjustments: the contributions of learning disability liaison nurses in 'Getting it right' for people with learning disabilities receiving general hospitals care. J Adv Nurs 2015;71:1552-63.

91 Moher D, Liberati A, Tetzlaff J, et al. Preferred reporting items for systematic reviews and meta-analyses: the PRISMA statement. PLoS Med 2009;6:e1000097. 